\title{
Special Issue on Experimental Methods in Environmental, Natural Resource, and Agricultural Economics
}

\author{
Kent D. Messer and James J. Murphy
}

Nearly two decades ago, Jason Shogren spoke at the Northeastern Agricultural and Resource Economics Association (NAREA) annual meeting about how the burgeoning field of experimental economics might be useful in addressing questions of interest to environmental and resource economists (Shogren 1993). At the time he spoke, in 1992, experimental economics was a niche field that primarily focused on nonmarket valuation techniques, social dilemma games, bargaining experiments, and testing game-theoretic models. As demonstrated in this special issue of the Agricultural and Resource Economics Review (ARER), things have certainly changed in ways that would have been hard to predict two decades ago, including the 2002 Nobel Prize awarded to Vernon Smith, the 2009 Nobel Prize awarded to Elinor Ostrom, publication of a field journal dedicated to experimental economics, and significant expansion in the range of topics and methodological approaches.

The changes that have occurred during the field's rapid growth, which started in the mid1990s and continues today, are evident in this issue's 14 papers that were written by 40 researchers from 27 institutions located in 9 countries on 5 continents. This special issue of ARER features primarily the papers presented at a methods workshop that sought to introduce young scholars to experimental economics techniques and to showcase examples of high quality re-

Kent D. Messer is Assistant Professor in the Department of Food and Resource Economics and the Department of Economics at the University of Delaware in Newark, Delaware. James J. Murphy is Rasmuson Chair of Economics in the Department of Economics at the University of Alaska, Anchorage. search that addressed environmental, natural resource, and agricultural economics issues. Tim Cason and Shogren, two leaders in the field, delivered invited presentations. This workshop, which followed the NAREA annual conference, was held in Burlington, Vermont, on June 9th and 10th, 2009. Financial support for the workshop and for publication of these papers in ARER was provided by the U.S. Environmental Protection Agency, the Farm Foundation, and the U.S. Department of Agriculture's Economic Research Service.

The papers in this special issue not only contribute to the classic experimental economics literature, but also illustrate how far the field has grown since the early 1990s. The papers cover a wide range of topics, from emissions auctions under the Regional Greenhouse Gas Initiative (Shobe et al. 2010) to managing a multispecies fishery (Anderson 2010), and use a variety of methods, including traditional laboratory experiments, field experiments, and hybrid approaches, such as Knapp and Murphy's (2010) field-in-thelab approach. What is common in these studies is the use of what Shogren, Parkhurst, and Hudson (2010) refer to as an experimental "mindset" which seeks to better understand the behavior of individuals, businesses, and organizations within the context of various institutional settings.

Shogren, invited to return as a keynote speaker for this workshop, notes how experimental methods have expanded from controlled laboratory settings with undergraduate students to include field experiments, neuroeconomics, and virtual reality. He discusses how behavioral economics has grown as a field and is now not only challenging parts of the traditional rational choice 
framework, but is also influencing economic policymakers at the highest levels. In addition to this methodological growth, the application of experimental methods to environmental and natural resource issues also underwent significant expansion in the mid- to late 1990s. Shogren's 1992 talk roughly coincided with two significant events in environmental policy that helped broaden experimental research to include more applied policy issues. The 1989 Exxon Valdez spill substantially expanded the existing literature on nonmarket valuation techniques, particularly regarding hypothetical bias and the development of calibration techniques to mitigate its effects. A key component of the 1990 Clean Air Act Amendments was the implementation of the U.S. Environmental Protection Agency's sulfur dioxide emissions trading program, one of the world's first successful large-scale cap-and-trade programs, leading to a surge in experimental research related to the design of emissions trading programs and, more broadly, on laboratory "testbedding" of new environmental policy initiatives. Testbedding of policies using experimental economics has been compared to using wind tunnels to test airplane design (Shogren 2004).

The workshop's other keynote speaker, Cason (2010), highlighted the growth in the use of experiments as testbeds for policy. Economics experiments are now providing valuable input into a wide variety of environmental, natural resource, and agricultural policy questions. Cason has been a major contributor to the emissions trading experimental literature, and his paper in this issue provides an excellent overview. Emission trading institutions, in particular, have received renewed research focus as a result of interest in the development of markets for a variety of environmental services, such as greenhouse gas emissions.

Both Cason's and Shogren's talks touched upon a theme that frequently emerged throughout the workshop and is a hot topic within the field of experimental economics: the relative merits of laboratory and field experiments. Around the late 1990s the landscape of experimental economics underwent a significant expansion with respect to both the range of topics studied and the experimental methods used. Until this time, the overwhelming majority of experiments were conducted in laboratory settings with university students. There was a natural progression with a significant surge in field studies using non-student subject pools. ${ }^{1}$ Joe Henrich (2000) was conducting field experiments with indigenous communities in Peru that laid the foundation for the 15 societies study that integrated ethnographic and experimental research in a cross-cultural comparison (Henrich et al. 2004). John List was concurrently working with sportscard dealers and found that experience matters in market exchange environments (List and Lucking-Reiley 2000).

The participants in Juan Camilo Cardenas' field experiments were rural villagers in Colombia whose livelihood depended upon successful management of a common pool resource. At the time, most experiments used neutral, context-free language to provide more experiment control. As Cason notes in this issue, the rationale for neutral framing was to reduce the likelihood that providing a context might unintentionally invoke certain preferences that the experimenter cannot observe. Cardenas was concerned that, in the absence of a context, subjects would introduce their own unobservable context, leading to less control. He argued that these villagers might bring a set of experiences and information about the context in a social dilemma that was quite different from that of university students (e.g., Cardenas and Ostrom 2004).

This special issue features two field experiments conducted in developing nations. Alevy, Cristi, and Melo (2010) worked with Chilean farmers to test the properties of a right-to-choose auction. Prior to the experiment, the research team acquired actual water volumes that were then offered for sale to farmers in two different auctions. Similar to Cardenas' experiments, the commodity being auctioned (water) is essential for the subjects' livelihoods and the experiments were framed using a context that was already familiar to the subjects. Their results suggest that the right-to-choose auction raises more revenue than a sequential auction and that varying risk attitudes can explain much of the difference in bidding behaviors observed. The paper by Lybbert et al. (2010) has a development focus. The authors note that their framed field experiments in Morocco, Peru, and Kenya not only offer benefits to researchers seeking to understand how the poor

\footnotetext{
' Our point is not that these studies are the first of their kind; rather, we note that around the late 1990s these lines of research underwent significant growth. Peter Bohm is generally credited as one of the pioneers in field experiments (Dufwenberg and Harrison 2008).
} 
respond to risk and to complex products, such as index insurance, but also provide an educational benefit by helping low-income farmers understand complex stochastic, dynamic processes.

Cason's (2010) paper discusses the merits of lab experiments, including the testbedding of proposed new rules and institutions, which is a focus of several papers in this special issue. For instance, Anderson (2010) tests a points-based system for managing the Northeast Multispecies Fishery that was proposed by an industry group. The experimental results show that harvesters are broadly responsive to this system of point prices, especially those with experience. Anderson concludes by suggesting that this type of system could be used to effectively manage a multispecies fishery to ensure acceptable economic and biological outcomes, assuming that the point prices can be readily adjusted over time. Doyon, Rondeau, and Mbala (2010) test new auction mechanisms for tradable egg production quotas in Quebec. They show that in thin markets, such as those common in highly concentrated agricultural industries, the truncated $k$-double auction can help decrease equilibrium prices with only moderate efficiency losses, thereby helping counter potential market power from oligopolies. Shobe et al. (2010) focus their use of experimental auctions to examine issues related to the direct sale of carbon emissions in the Regional Greenhouse Gas Initiative. Their paper tests the effects of "loose" and "strict" caps on the allocated allowances based on recent emission history. Their results suggest that auction revenue is lower compared to competitive benchmarks when a loose cap is used, but that these differences in revenue dissipate after a series of auctions.

Other papers are motivated by contemporary policy issues even if not directly testing alternative policy instruments. Hellerstein and Higgins (2010) use the U.S. Department of Agriculture's Conservation Reserve Program as the basis for their land conservation auction experiments. Their experimental results show that while capping the maximum amount a landowner can receive in environmental markets may have intuitive appeal as a way of reducing government expenditures, these caps actually can lead to an increase in expenditures. The authors argue that relaxing restrictions on the maximum bids from landowners could yield better results, especially when the quality of the land enrolled in the program matters. Knapp and Murphy's (2010) study of rent dissipation in competitive fisheries is motivated by the challenges faced in the Bristol Bay Alaska salmon fishery. They use a novel, interactive experiment that "brings the field into the lab." The task for subjects in their lab experiment was comparable to the field task under investigationactively harvesting from a limited resource stock. Subjects had to decide which harvesting device (measuring cups) to purchase, each of which had different harvesting capacities (cup size) and acquisition costs. The harvesting devices were then used to extract valuable items (dry beans) from a common pool resource (a large bowl). Bernard and $\mathrm{He}$ (2010) examine how bidding behavior in lab experiments involving the purchase of food might be influenced before and after a large increase in the prices for these goods in the field. Their results support the growing literature that suggests that researchers should be conscious of how field prices affect willingness-to-pay bids in experiments.

Other studies in this issue have policy implications, but the motivation is more general. For instance, Spraggon and Oxoby (2010) add to the nonpoint source pollution literature by evaluating how recommendations about choices and the presentation of payoff information might affect behavior. Their study suggests that the ambientbased policy instruments can be significantly improved when decision errors are reduced by providing a more robust description of the decision environment. Giordana, Montginoul, and Willinger (2010) investigate the relationship between static and dynamic externalities in a common pool resource, which is a critical issue in managing groundwater extraction from coastal aquifers where overexploitation can lead to irreversible damage from seawater intrusion. The results of their experiments did not support their initial hypothesis that the existence of static externalities would lead subjects to exhibit more pro-social behavior. Kotani, Messer, and Schulze (2010) use experiments to examine how changes in the incentive structure of tax refund and matching grant mechanisms leads to different levels of voluntary contributions to public goods. These authors argue that the "helping hand" that subjects provide through their contributions in settings that are not incentive-compatible reflect a partial revelation of de- 
mand for the good in question and therefore should be accounted for in benefit-cost analyses related to environmental projects.

Two studies address issues related to nonmarket valuation. Shogren, Parkhurst, and Hudson (2010) note in their paper that for controversial goods individuals may have either positive or negative values, and they study this within the context of willingness-to-pay and willingness-toaccept auctions. The authors conclude by expressing concerns that for controversial goods, the existence of positive and negative values could result in an overstatement of the costs relative to the benefits. Caplan, Aadland, and Macharia's (2010) research finds hypothetical bias in statedpreference public goods experiments in Botswana. Although there is an abundance of hypothetical bias studies, this study is one of the few that investigates this issue in a developing nation.

In summary, this special issue illustrates the breadth of current application of experimental economics techniques to issues of importance to environmental, resource, and agricultural economics. As Shogren departed from the workshop, he reported what a pleasure it was to see how the "seeds" that the pioneers of experimental economics helped plant have now "blossomed."

\section{References}

Alevy, J.E., O. Cristi, and O. Melo. 2010. "Right-to-Choose Auctions: A Field Study of Water Markets in the Limari Valley of Chile." Agricultural and Resource Economics Review 39(2): 213-226.

Anderson, C.M. 2010. "An Experimental Analysis of a PointsBased System for Managing Multispecies Fisheries." Agricultural and Resource Economics Review 39(2): 227-244.

Bernard, J.C., and N. He. 2010. "Confounded by the Field: Bidding in Food Auctions When Field Prices Are Increasing." Agricultural and Resource Economics Review 39(2): 275-287.

Caplan, A.J., D. Aadland, and A. Macharia. 2010. "Estimating Hypothetical Bias in Economically Emergent Africa: A Generic Public Good Experiment." Agricultural and Resource Economics Review 39(2): 344-358.

Cardenas, J.-C., and E. Ostrom. 2004. "What Do People Bring into the Game? Experiments in the Field about Cooperation in the Commons." Agricultural Systems 82(3): 307-326.

Cason, T.N. 2010. "What Can Laboratory Experiments Teach Us About Emissions Permit Market Design?" Agricultural and Resource Economics Review 39(2): 151-161.

Doyon, M., D. Rondeau, and R. Mbala. 2010. "Keep It Down: An Experimental Test of the Truncated $k$-Double Auction."
Agricultural and Resource Economics Review 39(2): 193212.

Dufwenberg, M., and G. Harrison. 2008. "Peter Bohm: Father of Field Experiments." Experimental Economics 11(3): 213-220.

Giordana, G.A., M. Montginoul, and M. Willinger. 2010. "Do Static Externalities Offset Dynamic Externalities? An Experimental Study of the Exploitation of Substitutable Common-Pool Resources." Agricultural and Resource Economics Review 39(2): 305-323.

Hellerstein, D., and N. Higgins. 2010. "The Effective Use of Limited Information: Do Bid Maximums Reduce Procurement Cost in Asymmetric Auctions?" Agricultural and Resource Economics Review 39(2): 288-304.

Henrich, J. 2000. "Does Culture Matter in Economic Behavior? Ultimatum Game Bargaining among the Machiguenga." American Economic Review 90(4): 973-979.

Henrich, J., R. Boyd, S. Bowles, H. Gintis, E. Fehr, and C. Camerer (eds.). 2004. Foundations of Human Sociality: Economic Experiments and Ethnographic Evidence in Fifteen Small-Scale Societies. New York: Oxford University Press.

Knapp, G., and J.J. Murphy. 2010. "Voluntary Approaches to Transitioning from Competitive Fisheries to Rights-Based Management: Bringing the Field into the Lab." Agricultural and Resource Economics Review 39(2): 245-261.

Kotani, K., K.D. Messer, and W.D. Schulze. 2010. "Matching Grants and Charitable Giving: Why People Sometimes Provide a Helping Hand to Fund Environmental Goods." Agricultural and Resource Economics Review 39(2): 324-343.

List, J.A., and D. Lucking-Reiley. 2000. "Demand Reduction in Multiunit Auctions: Evidence from a Sportscard Field Experiment." American Economic Review 90(4): 961-972.

Lybbert, T.J., F.B. Galarza, J. McPeak, C.B. Barrett, S.R. Boucher, M.R. Carter, S. Chantarat, A. Fadlaoui, and A. Mude. 2010. "Dynamic Field Experiments in Development Economics: Risk Valuation in Morocco, Kenya, and Peru." Agricultural and Resource Economics Review 39(2): 176192.

Shobe, W., K. Palmer, E. Myers, C. Holt, J. Goeree, and D. Burtraw. 2010. "An Experimental Analysis of Auctioning Emission Allowances Under a Loose Cap." Agricultural and Resource Economics Review 39(2): 162-175.

Shogren, J.F. 1993. "Experimental Markets and Environmental Policy." Agricultural and Resource Economics Review 22(2): 117-129.

2004. "Incentive Mechanism Testbeds: Discussion. American Journal of Agricultural Economics 86(5): 1218-1219.

Shogren, J.F., G.M. Parkhurst, and D. Hudson. 2010. "Experimental Economics and the Environment: Eliciting Values for Controversial Goods." Agricultural and Resource Economics Review 39(2): 133-150.

Spraggon, J., and R.J. Oxoby. 2010. “Ambient-Based Policy Instruments: The Role of Recommendations and Presentation." Agricultural and Resource Economics Review 39(2): 262-274. 